\title{
Utilização de Metodologias Ativas na Formação de Profissionais Humanizados
}

\author{
Fontes, Mírzia Lisboa; Andrade, Maisa Alves; Almeida, Thaynara Fontes; Araujo, \\ Jamilly Santos; Barreiro, Maria Socorro Claudino; Oliveira, Patricia Gois de \\ Universidade Federal de Sergipe — mlf_mlf@hotmail.com
}

INTRODUÇÃO: Desde a divulgação das Diretrizes Curriculares de Enfermagem os cursos de graduação têm missão de formar enfermeiros generalistas, críticos, reflexivos e humanistas, o que requer esforços das instituições formadoras na busca de estratégias que viabilizem desenvolvimento dessas habilidades. o novo método de ensino ABP (Aprendizagem Baseada em Problemas) surge como um inovador processo de formação acadêmica no qual abrange a concepção de saúde como um eixo integrador, levando ao desenvolvimento de uma visão mais humanista do paciente/cliente pelos futuros profissionais de saúde, focados nas necessidades e problemas de saúde do individuo como um todo e não apenas de forma fragmentada (focado na doença). OBJETIVO: Relatar a vivência de acadêmicos de Enfermagem da Universidade Federal de Sergipe/ Campus de Lagarto nas situações de ensino-aprendizado proposta pela subunidade Práticas de Ensino na Comunidade (PEC) para sua formação profissional humanizada. METODOLOGIA: Este trabalho caracteriza-se como um relato de experiência de discentes de enfermagem durante as atividades de PEC, baseada nas metodologias ativas. Participaram desse relato 39 discentes de enfermagem. RESULTADOS: As aulas de PEC são baseadas no Arco de Marguerez, onde os alunos observam a realidade, identifica problemas, teoriza as hipóteses de solução e em seguida aplica as intervenções na realidade. As atividades práticas são realizadas em Unidades Básicas de Saúde, escolas, comunidade e até mesmo no domicilio. Durante as atividades práticas, os alunos têm a oportunidade de fazer-aprender o cuidado de forma sensível, com um contato mais próximo do paciente, valorizando a dimensão ética e humana do cuidar. para os acadêmicos a humanização na assistência se inicia desde o contato inicial do paciente e de sua família com o serviço de saúde, até a realização de procedimentos ou intervenções que buscam a melhoria da qualidade de vida do usuário. CONCLUSÃO: a utilização de metodologias ativas contribui para a formação mais humanizada do profissional de saúde, pois promove um olhar mais critico e qualificado de reconhecimento do paciente como ser humano único e que necessita de cuidados individuais. e é no contexto da prática também que os alunos se desenvolvem enquanto pessoas, o que os torna mais fortalecidos para enfrentar a complexidade da vida profissional.

Fontes, Mírzia Lisboa; Andrade, Maisa Alves; Almeida, Thaynara Fontes; Araujo, Jamilly Santos; Barreiro, Maria Socorro Claudino; Oliveira, Patricia Gois de. Utilização de Metodologias Ativas na Formação de Profissionais Humanizados. In: Anais do Congresso Internacional de Humanidades \& Humanização em Saúde [= Blucher Medical Proceedings, num.2, vol.1]. São Paulo: Editora Blucher, 2014. ISSN 2357-7282 DOI 10.5151/medpro-cihhs-10777 